\title{
BMJ Open Time-dependent propensity-matched general population study of the effects of statin use on cancer risk in an interstitial lung disease and pulmonary fibrosis cohort
}

\author{
Jun-Jun Yeh (1) , ,,2 Jung-Nien Lai, ${ }^{3,4}$ Cheng-Li Lin, ${ }^{5,6}$ Chung-Y Hsu, ${ }^{7}$ \\ Chia-Hung Kao (iD) 7,8,9,10
}

To cite: Yeh J-J, Lai J-N, Lin C-L, et al. Time-dependent propensity-matched general population study of the effects of statin use on cancer risk in an interstitial lung disease and pulmonary fibrosis cohort. BMJ Open 2021;11:e047039. doi:10.1136/ bmjopen-2020-047039

- Prepublication history and additional supplemental material for this paper are available online. To view these files, please visit the journal online (http://dx.doi.org/10.1136/ bmjopen-2020-047039)

Received 17 November 2020 Accepted 29 August 2021

Check for updates

(C) Author(s) (or their employer(s)) 2021. Re-use permitted under CC BY-NC. No commercial re-use. See rights and permissions. Published by BMJ.

For numbered affiliations see end of article.

Correspondence to

Dr Chia-Hung Kao;

d10040@mail.cmuh.org.tw

\section{ABSTRACT}

Objective To determine the effect of statins on risk of cancer in patients with interstitial lung disease (ILD) and pulmonary fibrosis.

Setting We retrospectively enrolled patients with ILD and pulmonary fibrosis and divided them into two cohorts by statin use (statin users $(n=10036)$ and statin non-users $(n=10036))$.

Participants We selected patients with ILD and pulmonary fibrosis ( $\mathrm{N}=53 \mathrm{862})$ from Taiwan's National Health Insurance Research Database. Time-dependent Cox models were used to compare risk of cancer of propensity-matched statin users and non-users. Cumulative cancer incidence was analysed through Cox proportional regression. We calculated adjusted HRs (aHRs) and their 95\% Cls for cancer after adjusting for sex, age, comorbidities, and use of inhaled corticosteroids, oral steroids and statins.

Results Compared with statin non-users, the aHRs (95\% Cls) for statin users were 0.60 (0.55 to 0.65$)$ for cancer, 0.52 ( 0.35 to 0.78 ) for haematological malignancy, 0.52 ( 0.38 to 0.72 ) for cancer of the head and neck, 0.73 ( 0.59 to 0.89 ) for colorectal cancer, 0.34 (0.26 to 0.43 ) for liver cancer, 0.39 (0.23 to 0.67 ) for pancreatic cancer, 0.40 (0.17 to 0.96 ) for skin cancer, 0.67 (0.52 to 0.87 ) for breast cancer, 0.27 (0.14 to 0.54 ) for cervical cancer, 0.37 (0.30 to 0.46$)$ for other immunological cancers, $0.73(0.54$ to 0.98$)$ for bladder/kidney cancer and 0.88 (0.71 to 1.09$)$ for lung cancer.

Conclusion Statin use is associated with lower risk of cancer in the ILD and pulmonary fibrosis cohort.

\section{INTRODUCTION}

Cancer is associated with immune system dysregulation, infection, environment, lifestyle and ageing. Idiopathic pulmonary fibrosis (IPF) is an interstitial lung disease (ILD) that involves lung fibroblasts and shares many similar characteristics with cancer cells. Epithelial-mesenchymal transition, excessive micro-RNA, cell-to-cell communication and signal transduction pathways characterise the
Strengths and limitations of this study

- This novel study investigated the risk of cancer (particularly risk of immunological cancers) among patients with interstitial lung disease (ILD) and pulmonary fibrosis in the general population.

- Not all drugs used for ILD treatment (eg, hydroxychloroquine, interferon, anti-interleukin, azathioprine and non-steroidal anti-inflammatory drugs) were analysed.

- We did not stratify statin users by lipophilic and hydrophilic statin use for sensitivity analysis.

pathogenesis of ILD-IPF and lung cancer. ${ }^{12}$ These findings suggest that ILD, pulmonary fibrosis and lung cancer share common pathogenetic features. ${ }^{12}$

Immunological cancer includes HIVrelated cancers (eg, Kaposi's sarcoma and non-Hodgkin's lymphoma) and other virusrelated cancers such as oral cancer (caused by human papillomavirus (HPV)), liver cancer (caused by hepatitis B virus (HBV) or hepatitis C virus (HCV)), Hodgkin's and non-Hodgkin's lymphoma (associated with Epstein-Barr virus (EBV)), and colon cancer (irritable bowel syndrome-associated virus (IBS-V)). HIV, HPV, HBV, HCV, EBV and IBS-V are associated with ILD, fibrosis and immunological cancers. ${ }^{3-7}$ The coronavirus is also associated with ILD and pulmonary fibrosis, suggesting that this virus may play a role in the higher mortality of patients with cancer. $^{8-10}$

Statins have multiple pleiotropic effects (eg, suppression of inflammation, reduction of oxidative stress and reduction of $\mathrm{T}$ cell activation) that have implications for immunomodulatory diseases. Researchers have speculated that statins play an auxiliary role 
in attenuating cancer formation in patients with ILD and pulmonary fibrosis. First, matrix metalloproteinases (MMPs) are essential in IPF progression, and the overexpression of MMPs in cancer formation, ILD and pulmonary fibrosis has been reported. ${ }^{11-13}$ This suggests that statins that inhibit MMPs can play an auxiliary role in attenuating IPF exacerbation, leading to a lower risk of cancer formation in ILD and pulmonary fibrosis. ${ }^{11-14}$ Second, the optimal expression of ACE2 and angiotensin 1-7 suppresses cancer formation in ILD and pulmonary fibrosis through overexpression of ACE. ${ }^{15-19}$ An increase in interleukin 6 (IL-6) also promotes tumour formation. ${ }^{20}{ }^{21}$ Statins that play an auxiliary role in enhancing the effects of ACE2 and angiotensin 1-7 and attenuating the effects of IL- $-6^{17} 19$ thus play an auxiliary role in inhibiting immunological cancers such as oral cancer, colorectal cancer, liver cancer and lymphoma evolution. Third, the epidermal growth factor receptor (EGFR), which is associated with hepatoma-related virus infections involving viruses such as HBV and HCV, is involved in the association of coronavirus with ILD and pulmonary fibrosis (eg, IPF).$^{22}{ }^{23}$ Nguyen et al ${ }^{24}$ reported that statins may play a supportive role in attenuating the effect of EGFR overexpression in patients with cancer. Collectively, the aforementioned findings indicate that statins are associated with a lower risk of immunological cancers in patients with ILD and pulmonary fibrosis, which are closely associated with virus infections. ${ }^{81825-27}$

To date, no study has examined the role of statins in the risk of immunological cancer during treatment of ILD and pulmonary fibrosis. Thus, we investigated the relationship between statin use and cancer incidence in general population patients with ILD and pulmonary fibrosis.

\section{MATERIALS AND METHODS}

\section{Patient and public involvement}

Taiwan's National Health Insurance (NHI) programme was launched in March 1995 and currently provides insurance coverage to $99 \%$ of Taiwan's 23 million population. Patients included in this retrospective population-based cohort study were selected from a subset of the National Health Insurance Research Database (NHIRD). We used data from the Longitudinal Health Insurance Database 2000 (LHID 2000), which comprises 1000000 randomly sampled beneficiaries who are enrolled in the NHI programme. The database contains extensive inpatient and outpatient data of all insured individuals, including their demographic characteristics (eg, age, sex and socioeconomic status) and diagnostic and therapeutic information such as those relating to chest X-rays (CXRs), CT, pathology, pulmonary function tests, biochemistry data, chemotherapy, radiotherapy and mechanical ventilation. The disease codes used in the LHID 2000 correspond to those of the International Classification of Diseases, Ninth Revision, Clinical Modification (ICD-9-CM). Because patients (ie, insured individuals) were deidentified to protect their privacy, informed consent was not required.

\section{Study participants}

We selected patients who were diagnosed as having ILD and pulmonary fibrosis $(\mathrm{N}=53862)$ between 1 January 2000 and 31 December 2013. The ICD-9-CM diagnosis codes used to identify patients with ILD and pulmonary fibrosis were as follows: 135, sarcoidosis; 237.7, neurofibromatosis; 272.7, lipidoses; 277.3, amyloidosis; 277.8, other specified metabolic disorders including eosinophilic granuloma; 446.21, Goodpasture syndrome; 446.4, Wegener granulomatosis; 495, extrinsic allergic alveolitis; 500, coal workers' pneumoconiosis; 501, asbestosis; 502, pneumoconiosis due to other silica or silicates; 503, pneumoconiosis due to other types of inorganic dust; 504, pneumonopathy due to inhalation of other types of dust; 505 , unspecified pneumoconiosis; 506.4, chronic respiratory conditions due to chemicals, gases, fumes and vapours; 508.1, chronic and other pulmonary manifestations due to radiation; 508.8, respiratory conditions due to other specified external agents; 515, postinflammatory pulmonary fibrosis; 516, other alveolar and parietoalveolar pneumonopathy; 516.30, idiopathic interstitial pneumonia not otherwise specified; 516.31, IPF; 516.32, idiopathic non-specific interstitial pneumonitis; 516.33, acute interstitial pneumonia; 516.34, respiratory bronchiolitis ILD; 516.35, idiopathic lymphoid interstitial pneumonia; 516.36, cryptogenic organising pneumonia; 516.37, desquamative interstitial pneumonia; 517.2, lung involvement in systemic sclerosis; 517.8, lung involvement in other diseases classified elsewhere; 518.3, pulmonary eosinophilia; 555.0555.2, Crohn's disease; 558.9, granulomatous enteritis; 710 , diffuse diseases of connective tissue; 710.1, systemic sclerosis; 710.2, Sjogren's disease; 710.3, dermatomyositis; 710.4, polymyositis; 714.81, rheumatoid lung; 720, ankylosing spondylitis and other inflammatory spondylopathies; and 759.5, tuberous sclerosis. ${ }^{28}$ The incidence of lung cancer can reach $57.6 \%$ in patients with post-IPF and $36.5 \%$ in patients diagnosed synchronously as having lung cancer and IPF. ${ }^{1}$ Patients with Crohn's disease have a higher incidence of IPF due to the association between IPF and IBS; therefore, we included Crohn's disease in our analysis. ${ }^{29} 30$

The date of the first diagnosis of ILD and pulmonary fibrosis was defined as the index date. According to their statin use during the study period, the enrolled patients were divided into two cohorts $(\mathrm{N}=53862)$, namely statin users $(n=31738)$ and statin non-users $(n=22124)$ cohorts. Because the frequency of medication use varied among the participants, their statin use status was assessed every 6 -month period. Patients with a history of cancer diagnosed before the index date (ICD-9-CM codes 140-208) were excluded.

The diagnosis of ILD and pulmonary fibrosis in Taiwan is based on clinical history, CXR, high-resolution CT and pathology. ${ }^{28}$ The coding of ILD and pulmonary fibrosis in the NHIRD was established according to these strict standards. 


\section{Outcome variables}

The main outcome was diagnosis of a new cancer. To define cancer precisely, all patients enrolled in this study were linked to the registry of the Catastrophic Illness Patient Database. Our study outcomes comprised cancers of haematology (ICD-9-CM codes 200-208), head and neck (140-149), oesophagus (150), stomach (151), colon and rectum (153 and 154, respectively), liver (155), pancreas (157), lung (162), skin (173), breast (174), cervix (180), endometrium (182), ovary (183), prostate (185), kidney (188 and 189), brain (191), thyroid (193), and other conditions that were related to immunological cancers (other immunological cancers; 172, malignant melanoma; 176, Kaposi's sarcoma). ${ }^{31}$ All patients were tracked until cancer diagnosis, withdrawal from the NHI or the end of 2013.

Patients who withdrew from the NHI system before the end of the study period were excluded from the present study. To prevent confounding factors from influencing the cancer risk results of the study groups, patients who previously had cancer and those who received anticancer therapy were excluded from the present study. Patients who had used statins for less than 3 months were regarded as new users.

\section{Potential comorbidities and drugs}

The following potential comorbidities were included in the present study: sleep disorder, diabetes, hypertension, hyperlipidaemia, mental disorders, alcohol-related illnesses, chronic kidney disease, gout, coronary artery disease and stroke. Patients' use of inhaled corticosteroids (ICS) and oral steroids (OS) for asthma or chronic obstructive pulmonary disease (COPD) was also considered. All comorbidities and drugs were diagnosed using ICD-9-CM codes, which were examined in previous studies. $^{32}$

\section{Statistical analysis}

Differences in age, sex and comorbidities between statin users and non-users were examined using the $\chi^{2}$ test. Differences in mean age were examined using t-tests. The overall incidence rate of cancer (per 1000 person-years) and the incidence rates (per 1000 person-years) specific to sex, age and follow-up time were estimated. Because the dynamic frequency of statin (hydrophilic and lipophilic statins) use may introduce bias to the study results, ${ }^{17}$ we analysed statin use as a time-dependent covariate through the quantification of participants' statin use status for every 6-month period. Cox proportional hazards models with time-dependent exposure covariates were used to compute the HR with $95 \%$ CI. To further control for potential confounding factors, we performed sensitivity analyses to match the two groups on the basis of their propensity score at a 1:1 ratio. The propensity score was calculated according to age-related, sex-related and cancer-related comorbidities using logistic regression. Moreover, time-dependent Cox models were employed to compare the risk of cancer of propensity-matched statin users $(\mathrm{n}=10036)$ and non-users $(\mathrm{n}=10036)$. The KaplanMeier method was used to obtain the cancer incidence cumulative curves of statin users and non-users, and these curves were subsequently examined by performing logrank tests. A two-tailed $\mathrm{p}$ value of $<0.05$ indicated statistical significance. All analyses were conducted using SAS statistical software (V.9.4).

\section{RESULTS}

The characteristics of the cohort are presented in table 1. A total of 53862 patients with ILD and pulmonary fibrosis were enrolled in the present study. We identified 31738 statin users and 22124 statin non-users in the non-matched cohorts. After conducting propensity score matching, 10036 statin users and 10036 non-users were selected for the matched cohorts. Between the two non-matched cohorts, significant differences in age and comorbidities were observed $(p<0.001)$. Between the two matched cohorts, significant differences were only noted for $\operatorname{sex}(p=0.02)$ and alcohol-related illnesses $(p=0.01)$. The mean age of those in the non-matched cohort was 55.3 years, and approximately $56 \%$ of the study participants were women. The results are presented in figure 1 , which indicates that the cumulative incidence of cancer was lower among statin users relative to statin non-users.

\section{Time-dependent covariates in the non-matched cohort}

The incidence and risk for all cancers were significantly lower among statin users relative to statin non-users (17.5 vs 24.2 per 1000 person-years), with an adjusted HR (aHR) of 0.59 (95\% CI 0.55 to 0.63 ) after controlling for covariates. Stratification according to cancer site revealed that relative to statin non-users, statin users exhibited significantly lower risk for haematological malignancy ( $\mathrm{aHR}=0.59 ; 95 \% \mathrm{CI} 0.43$ to 0.81$)$, head and neck cancer (aHR $=0.55 ; 95 \%$ CI 0.43 to 0.71$)$, colorectal cancer $(\mathrm{aHR}=0.78 ; 95 \%$ CI 0.67 to 0.92$)$, liver cancer $(\mathrm{aHR}=0.30$; $95 \%$ CI 0.25 to 0.36$)$, pancreatic cancer $(\mathrm{aHR}=0.42$; $95 \%$ CI 0.28 to 0.63 ), lung cancer ( $\mathrm{aHR}=0.80 ; 95 \% \mathrm{CI}$ 0.67 to 0.92$)$, breast cancer $(\mathrm{aHR}=0.62 ; 95 \%$ CI 0.50 to $0.78)$, other immunological cancers $(\mathrm{aHR}=0.35 ; 95 \% \mathrm{CI}$ 0.29 to 0.41$)$, cervical cancer $(\mathrm{aHR}=0.33 ; 95 \% \mathrm{CI} 0.21$ to $0.53)$, kidney cancer $(\mathrm{aHR}=0.74 ; 95 \% \mathrm{CI} 0.59$ to 0.96$)$ and other cancers $(\mathrm{aHR}=0.61 ; 95 \%$ CI 0.46 to 0.80$)$ (table 2$)$.

Data on specific cancers that were associated with statistically significant results (table 2) were further stratified by sex, age and follow-up time. Among male patients, statin users exhibited a significantly lower risk (compared with statin non-users) for all cancers $(\mathrm{aHR}=0.61 ; 95 \% \mathrm{CI}$ 0.56 to 0.67$)$, head and neck cancer $(\mathrm{aHR}=0.57 ; 95 \% \mathrm{CI}$ 0.44 to 0.75$)$, colorectal cancer $(\mathrm{aHR}=0.70 ; 95 \%$ CI 0.56 to 0.87 ), liver cancer $(\mathrm{aHR}=0.36 ; 95 \% \mathrm{CI} 0.28$ to 0.45$)$, pancreatic cancer $(\mathrm{aHR}=0.31 ; 95 \% \mathrm{CI} 0.17$ to 0.58$)$ and other immunological cancers $(\mathrm{aHR}=0.40$; $95 \%$ CI 0.33 to 0.50$)$. Among female patients, statin users exhibited a significantly lower risk (compared with statin nonusers) for all cancers $(\mathrm{aHR}=0.56 ; 95 \%$ CI 0.51 to 0.62$)$, 
Table 1 Distribution of demographic and clinical comorbid status in the study cohorts

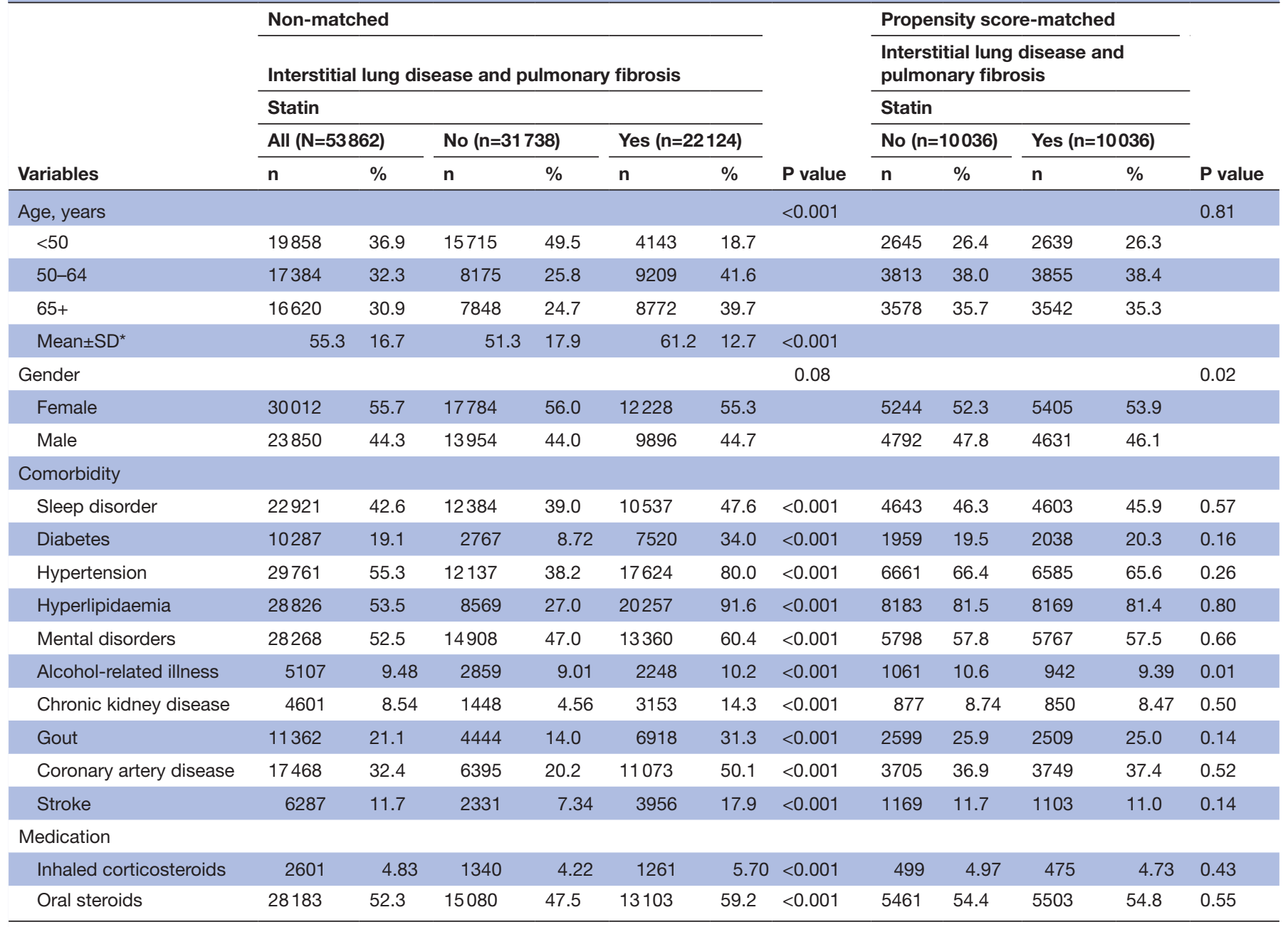

$\chi^{2}$ test.

${ }^{*}$ t-test.

haematological malignancy $(\mathrm{aHR}=0.47 ; 95 \% \mathrm{CI} 0.30$ to $0.73)$, head and neck cancer $(\mathrm{aHR}=0.40 ; 95 \%$ CI 0.18 to 0.87 ), liver cancer $(\mathrm{aHR}=0.22 ; 95 \% \mathrm{CI} 0.15$ to 0.30$)$, pancreatic cancer $(\mathrm{aHR}=0.53 ; 95 \% \mathrm{CI} 0.30$ to 0.94$)$ and other immunological cancers $(\mathrm{aHR}=0.29 ; 95 \% \mathrm{CI} 0.22$ to 0.37) (table 3).

Our age-stratified analysis demonstrated that statin use was significantly associated with a lower risk for all cancers among patients aged $\geq 50$ years. However, among patients aged $\leq 49$ years, statin use was only associated with lower risk for haematological malignancy $(\mathrm{aHR}=0.33$; 95\% CI 0.13 to 0.87$)$, head and neck cancer $(\mathrm{aHR}=0.40 ; 95 \% \mathrm{CI}$ 0.24 to 0.65$)$, other immunological cancers $(\mathrm{aHR}=0.30$; $95 \%$ CI 0.18 to 0.50$)$ and kidney cancer $(\mathrm{aHR}=0.33$; $95 \%$ CI 0.11 to 0.97 ) (table 4 ).

Analysis of the data stratified by follow-up time revealed that most cancers developed within the first 0.5 years. The follow-up periods of 0.5-1 year, 1-2 years and $>2$ years were associated with a lower risk for all cancers. The application of the multivariable adjusted Cox proportional hazards model revealed that relative to statin non-users, statin users exhibited a significantly lower risk for cancer during the follow-up periods (table 5).

\section{Time-dependent covariates in propensity score-matched sensitivity analysis}

Table 6 presents the sensitivity analysis for propensitymatched statin users and non-users. Our results for the association between statin use and risk of cancer are similar to the key findings reported by other studies (table 2). In the matched cohorts, statin users exhibited significantly lower risk for all cancers $(\mathrm{aHR}=0.60 ; 95 \% \mathrm{CI}$ 0.55 to 0.65$)$, haematological malignancy $(\mathrm{aHR}=0.52$; $95 \%$ CI 0.35 to 0.78$)$, head and neck cancer $(\mathrm{aHR}=0.52$; $95 \%$ CI 0.38 to 0.72$)$, colorectal cancer $(\mathrm{aHR}=0.73$; $95 \%$ CI 0.59 to 0.89 ), liver cancer $(\mathrm{aHR}=0.34 ; 95 \% \mathrm{CI}$ 0.26 to 0.43$)$, pancreatic cancer $(\mathrm{aHR}=0.39 ; 95 \% \mathrm{CI}$ 0.23 to 0.67$)$, skin cancer $(\mathrm{aHR}=0.40 ; 95 \% \mathrm{CI} 0.17$ to $0.96)$, breast cancer $(\mathrm{aHR}=0.67 ; 95 \%$ CI 0.52 to 0.87$)$, other immunological cancers $(\mathrm{aHR}=0.37 ; 95 \% \mathrm{CI} 0.30$ to 0.46 ), cervical cancer $(\mathrm{aHR}=0.27 ; 95 \%$ CI 0.14 to 0.54$)$, kidney cancer $(\mathrm{aHR}=0.73 ; 95 \%$ CI 0.54 to 0.98$)$ and other 


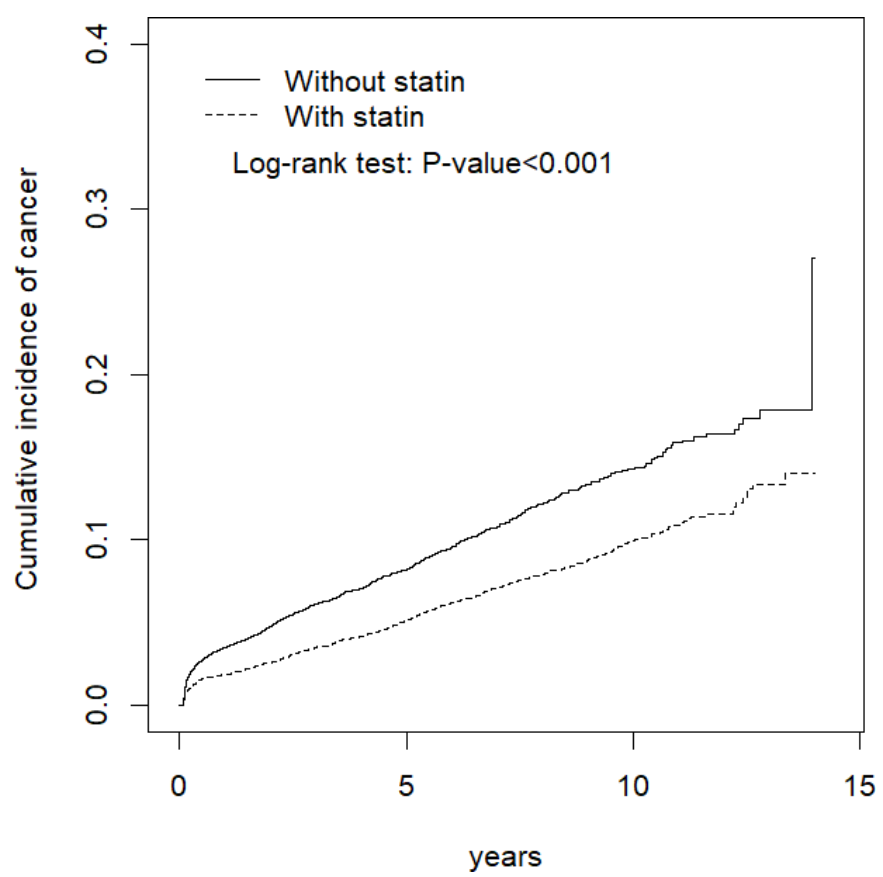

Figure 1 Cumulative incidence of cancer was lower in statin users than in non-statin controls.

cancers $(\mathrm{aHR}=0.62 ; 95 \%$ CI 0.44 to 0.88$)$. No association between statin use and risk for lung cancer was observed $(\mathrm{aHR}=0.88 ; 95 \%$ CI 0.71 to 1.09$)$.

\section{DISCUSSION}

The first major finding of the present study was that relative to patients with ILD and pulmonary fibrosis who did not take statins, those who took statins exhibited a lower risk for cancers such as colorectal cancer, liver cancer, breast cancer, Hodgkin's lymphoma and Kaposi's sarcoma. ${ }^{25}$ These cancers are associated with the overexpression of cytokines (such as IL-6), ACE activity, EGFR, vascular endothelial growth factor (VEGF) and MMPs and are regarded as immunological cancers. ${ }^{3-6}$ The axis formed by ACE2 is a potent counter-regulator against ACE activity. ${ }^{33}$ Statins may play an auxiliary role in enhancing the ability of ACE2 to correct the imbalance of ACE/ACE2, inhibit IL-6 activity, and attenuate the activity of EGFR, VEGF and MMPs. Thus, patients with ILD and pulmonary fibrosis who use statins exhibit a lower risk for cancer formation (relative to statin non-users), even in the presence of virus infections (see online supplemental figure). ${ }^{33-35}$

In the present study, patients with ILD and pulmonary fibrosis who used statins exhibited a high prevalence of obesity-related diseases such as mental disorder $(60.4 \%)$, hyperlipidaemia $(91.6 \%)$, hypertension $(80.0 \%)$ and coronary artery disease $(50.1 \%) .{ }^{20} 36$ These comorbidities aggravated the overexpression of EGFR signalling and VEGF, which are associated with cancer formation among patients with ILD and pulmonary fibrosis. ${ }^{1822}$ Statin use may play an auxiliary role in enhancing the effect of angiotensin 1-7, correction of ACE/ACE2 imbalance, and inhibition of the EGFR and VEGF transactivation through a Mas receptor-dependent pathway. ${ }^{18} 19$ These findings suggest that statin use is associated with a lower risk of cancer in patients with ILD and progressive pulmonary fibrosis, particularly when they also have the aforementioned comorbidities. ${ }^{25} 36-39$

Nielsen et $a l^{40}$ reported that patients who used statins (regardless of whether their daily dose level was low, moderate or high) exhibited a lower aHR for cancerrelated mortality compared with those who did not use statins. The low aHRs for cancer-related mortality that were associated with the $<0.5$ year and $0.5-1$ year follow-up periods among statin users suggest that early statin use (ie, within 1 year after diagnosis of ILD) is associated with a lower risk of cancer among patients with ILD. A low aHR for cancer-related mortality was also observed in the $>2$-year follow-up period. A metaanalysis reported that for follow-up periods from 2.5 to 10.7 years, statin use was independently associated with a lower risk of liver cancer in patients with $\mathrm{HBV}$ or HCV infection that was related to ILD and pulmonary fibrosis; these results are consistent with those reported in our study. ${ }^{41}$ Another large-scale study compared the use of statins among 29498 patients with colorectal cancer and discovered that statin use at the time of cancer diagnosis is associated with enhanced overall survival. The benefit of statin use appears to persist regardless of cancer stage, location and presence of other cardiovascular comorbidities. ${ }^{42}$ A novel finding of our study was that relative to the other follow-up periods, a higher number of cancer incidents occurred within 6 months of ILD and pulmonary fibrosis diagnosis. Notably, relative to the patients with ILD and pulmonary fibrosis who did not use statins, those who used statins exhibited a lower aHR for cancer incidence.

These findings highlight the benefits of early statin use for patients with ILD and pulmonary fibrosis who also have comorbidities such as obesity-related diseases. Statins may play an auxiliary role in attenuating the risk of haematological malignancy, head and neck cancer, colorectal cancer, liver cancer, pancreatic cancer and breast cancer, which are associated with obesity among patients with ILD and pulmonary fibrosis who are aged $\geq 50$ years. For example, the prevalence of hyperlipidaemia reached $91.6 \%$ in patients with ILD and pulmonary fibrosis who were statin users. Statin use reduced low-density lipoprotein cholesterol (LDL-C) levels, increased high-density lipoprotein cholesterol (HDL-C) levels and attenuated the incidence of obesity-related diseases, all of which contributed to the lower risk of cancer among statin users relative to statin non-users. A previous study reported that lower LDL-C and higher HDL-C levels were associated with a lower risk of cancer, which is consistent with our findings. ${ }^{3643}$ However, young adult patients used statins less frequently (compared with patients from other age groups) because they made fewer 
Table 2 Overall incidence of cancer (per 1000 person-years) and estimated HR in patients with interstitial lung disease with statin compared with patients with interstitial lung disease and pulmonary fibrosis without statin by Cox proportional hazard model with time-dependent covariates in non-matched cohorts

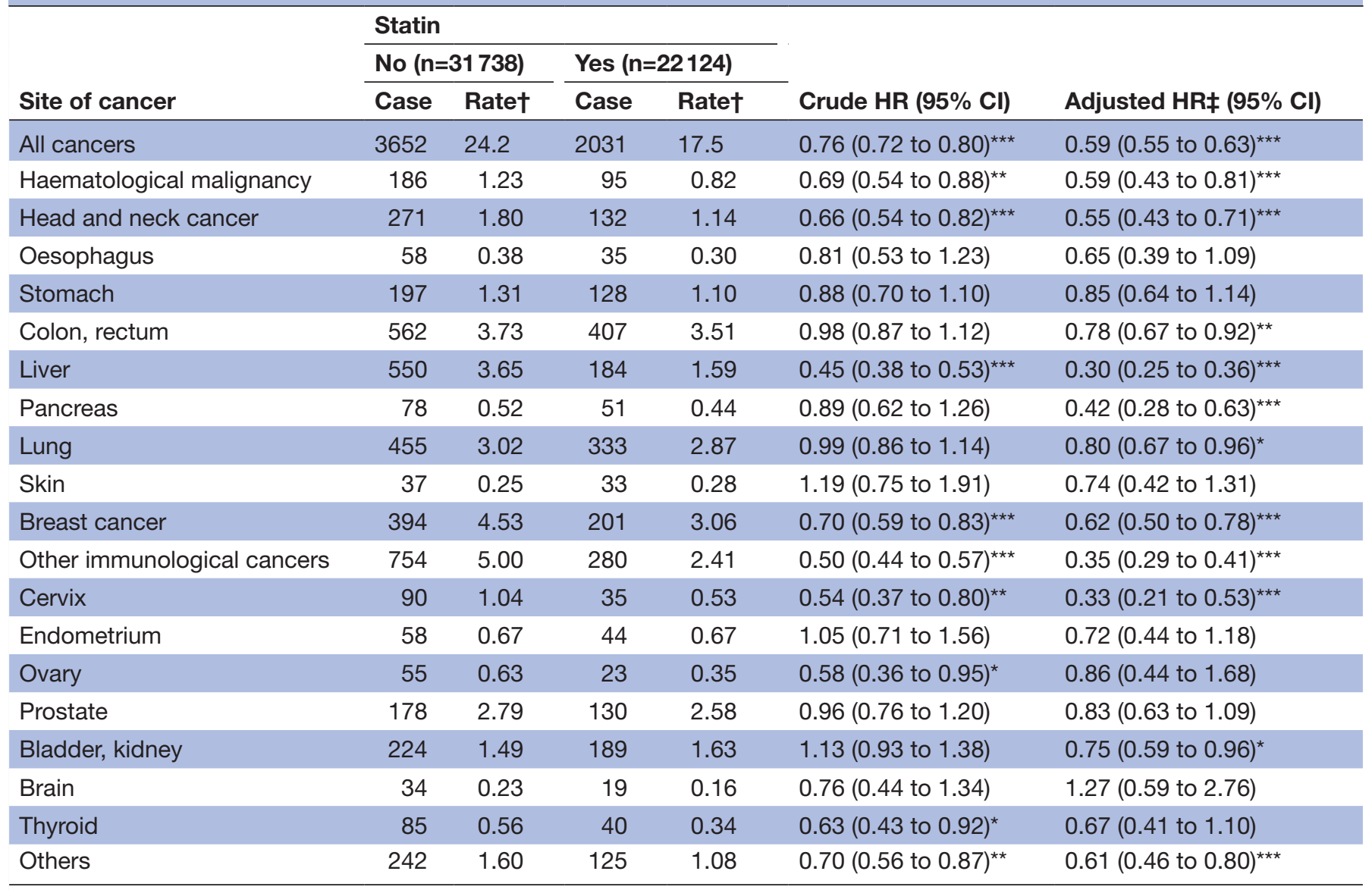

${ }^{\star} \mathrm{P}<0.05,{ }^{\star *} \mathrm{P}<0.01,{ }^{* \star \star} \mathrm{P}<0.001$.

†Rate, incidence rate, per 1000 person-years; crude HR, relative HR.

$\ddagger$ Adjusting for age, gender, comorbidity of sleep disorder, diabetes, hypertension, hyperlipidaemia, mental disorders, alcohol-related illness, chronic kidney disease, gout, CAD and stroke, and ICS and OS medication.

CAD, coronary artery disease; ICS, inhaled corticosteroids; OS, oral steroids.

medical visits; thus, this group of patients did not take sufficient dose of statin to achieve the auxiliary attenuation effect of statins on cancer incidence. Consequently, patients aged $\leq 49$ years who used statin did not exhibit a lower risk for colorectal, pancreatic and lung cancer.

It is important to note that COPD in smokers is associated with risk of pulmonary fibrosis and cancer. ICS, OS and statins ${ }^{44}$ play crucial roles in COPD exacerbation and pulmonary fibrosis. ${ }^{45}$ In the present study, the association of these three drugs with risk of cancer incidence was examined, and we discovered that statin use was independently associated with risk of cancer in the ILD and pulmonary fibrosis cohort.

Our results suggest that statin use played an auxiliary role in reducing cancer incidence among patients with ILD and pulmonary fibrosis. Notably, our study revealed that statin use led to a lower risk of cancer in the <0.5 year, 0.5-1 year and $>1$ year follow-up periods. These findings should be further verified through prospective randomised trials.

\section{Strengths}

First, this was a large-scale study aimed at detecting risk of cancer, particularly risk of immunological cancers, among patients in the general population who have ILD and pulmonary fibrosis. Second, we performed propensity score matching to avoid introducing baseline bias. Third, we conducted a timedependent analysis to eliminate immortal time bias. Fourth, we stratified the follow-up time into periods of $<0.5,0.5-1,1-2,2-3$ and $\geq 3$ years to avoid introducing lag-time bias. Fifth, we stratified individuals by age, sex and cancer type to validate our results, and we discovered that the risk for most cancers such as immunological cancers was lower in the statin user group, which was in line with the primary outcome. Sixth, we replaced the lifestyle variable with associated comorbidities. For example, hypertension and 
Table 3 Cox proportional hazard model with time-dependent covariates with HR and 95\% Cl of type of cancer associated with statin stratified by sex among patients with interstitial lung disease and pulmonary fibrosis in non-matched cohorts

\begin{tabular}{|c|c|c|c|c|}
\hline \multirow[b]{3}{*}{ Site of cancer } & \multicolumn{2}{|c|}{ Male with statin } & \multicolumn{2}{|c|}{ Female with statin } \\
\hline & No $(n=12228)$ & Yes $(n=9896)$ & No $(n=17784)$ & Yes $(n=13954)$ \\
\hline & \multicolumn{2}{|c|}{ Adjusted HR† (95\% Cl) } & \multicolumn{2}{|c|}{ Adjusted HR† (95\% Cl) } \\
\hline Haematological malignancy & 1 (reference) & $0.73(0.47$ to 1.14$)$ & 1 (reference) & $0.47(0.30 \text { to } 0.73)^{\star \star *}$ \\
\hline Head and neck cancer & 1 (reference) & $0.57(0.44 \text { to } 0.75)^{\star \star \star}$ & 1 (reference) & $0.40(0.18 \text { to } 0.87)^{\star}$ \\
\hline Liver & 1 (reference) & $0.36(0.28 \text { to } 0.45)^{\star \star \star}$ & 1 (reference) & $0.22(0.15 \text { to } 0.30)^{\star \star \star}$ \\
\hline Pancreas & 1 (reference) & $0.31(0.17 \text { to } 0.58)^{\star \star \star}$ & 1 (reference) & $0.53(0.30 \text { to } 0.94)^{\star}$ \\
\hline Lung & 1 (reference) & 0.82 (0.65 to 1.03$)$ & 1 (reference) & 0.76 (0.58 to 1.00$)$ \\
\hline Other immunological cancers & 1 (reference) & $0.40(0.33 \text { to } 0.50)^{\star \star \star}$ & 1 (reference) & $0.29(0.22 \text { to } 0.37)^{\star \star \star}$ \\
\hline Bladder, kidney & 1 (reference) & 0.74 (0.53 to 1.02$)$ & 1 (reference) & $0.76(0.53$ to 1.10$)$ \\
\hline
\end{tabular}

${ }^{*} \mathrm{P}<0.05,{ }^{* *} \mathrm{P}<0.01,{ }^{* \star *} \mathrm{P}<0.001$.

†Adjusted HR: multivariable analysis including age, gender, comorbidity of sleep disorder, diabetes, hypertension, hyperlipidaemia, mental disorders, alcohol-related illness, chronic kidney disease, gout, CAD and stroke, and ICS and OS medication.

CAD, coronary artery disease; ICS, inhaled corticosteroids; OS, oral steroids.

alcohol-related illnesses replaced obesity, hyperlipidaemia replaced exercise and obesity, gout replaced diet, stroke replaced air pollution, sleep disorder replaced occupation, mental disorder replaced economic condition, and ICS and OS use replaced smoking-related diseases such as COPD (in Taiwan, up to $82.9 \%$ of patients with COPD are smokers) or COPD with asthma $(78.1 \%$ and $25.6 \%$ of such patients received OS and ICS, respectively). ${ }^{32}$ We tracked the patients in Taiwan with ILD and pulmonary fibrosis and obtained data relating to their IL-6, ACE, ACE2, angiotensin 1-7, epidermal growth factor, VEGF, CXR and CT results. ${ }^{46}$ Furthermore, the coronavirus and cancers hijack the same parts of human cells to spread; therefore, this study suggests the potential of using statins to manage cancers associated with virus infections in patients with ILD and pulmonary fibrosis.

\section{Limitations}

In this study, not all drugs used for ILD treatment, such as hydroxychloroquine, interferon, anti-interleukin, azathioprine and non-steroidal anti-inflammatory drugs, were analysed. Moreover, the NHIRD does not provide cytokine data. However, in Taiwan, biochemistry data

Table 4 Cox proportional hazard model with time-dependent covariates with $\mathrm{HR}$ and 95\% $\mathrm{Cl}$ of type of cancer associated with statin stratified by age among patients with interstitial lung disease and pulmonary fibrosis in non-matched cohorts

\begin{tabular}{|c|c|c|c|c|}
\hline \multirow{3}{*}{ Site of cancer } & \multicolumn{2}{|l|}{ Age $\leq 49$ years } & \multicolumn{2}{|l|}{ Age $\geq 50$ years } \\
\hline & \multicolumn{2}{|l|}{ Statin } & \multicolumn{2}{|l|}{ Statin } \\
\hline & No $(n=15715)$ & Yes $(n=4143)$ & No $(n=16023)$ & Yes $(n=17981)$ \\
\hline All cancers & 1 (reference) & $0.46(0.37 \text { to } 0.57)^{\star \star \star}$ & 1 (reference) & $0.58(0.54 \text { to } 0.62)^{\star \star \star}$ \\
\hline Haematological malignancy & 1 (reference) & $0.33(0.13 \text { to } 0.87)^{\star}$ & 1 (reference) & $0.60(0.43 \text { to } 0.83)^{\star \star}$ \\
\hline Colon, rectum & 1 (reference) & 0.65 (0.34 to 1.25$)$ & 1 (reference) & $0.75(0.64 \text { to } 0.89)^{\star \star \star}$ \\
\hline Liver & 1 (reference) & $0.33(0.17 \text { to } 0.63)^{\star \star \star}$ & 1 (reference) & $0.28(0.23 \text { to } 0.34)^{\star \star \star}$ \\
\hline Pancreas & 1 (reference) & $0.28(0.02$ to 3.50$)$ & 1 (reference) & $0.40(0.26 \text { to } 0.61)^{\star \star \star}$ \\
\hline Lung & 1 (reference) & 1.06 (0.53 to 2.12$)$ & 1 (reference) & $0.75(0.63 \text { to } 0.90)^{\star \star}$ \\
\hline Other immunological cancers & 1 (reference) & $0.30(0.18 \text { to } 0.50)^{\star \star \star}$ & 1 (reference) & $0.33(0.28 \text { to } 0.39)^{\star \star \star}$ \\
\hline
\end{tabular}

${ }^{\star} \mathrm{P}<0.05,{ }^{\star \star} \mathrm{P}<0.01,{ }^{* \star *} \mathrm{P}<0.001$.

†Adjusted HR: multivariable analysis including age, gender, comorbidity of sleep disorder, diabetes, hypertension, hyperlipidaemia, mental disorders, alcohol-related illness, chronic kidney disease, gout, CAD and stroke, and ICS and OS medication.

CAD, coronary artery disease; ICS, inhaled corticosteroids; OS, oral steroids. 
Table 5 Incidence and HR of cancer between subjects with and without statin among patients with interstitial lung disease and pulmonary fibrosis in non-matched cohorts using Cox proportional hazard model

\begin{tabular}{|c|c|c|c|c|c|c|c|c|}
\hline \multirow{3}{*}{$\begin{array}{l}\text { Follow-up } \\
\text { years }\end{array}$} & \multicolumn{6}{|l|}{ Statin } & \multirow[b]{3}{*}{ Crude HR $(95 \% \mathrm{Cl})$} & \multirow[b]{3}{*}{ Adjusted HR $¥(95 \% \mathrm{Cl})$} \\
\hline & \multicolumn{3}{|l|}{ No } & \multicolumn{3}{|l|}{ Yes } & & \\
\hline & Event & PY & Rate† & Event & PY & Rate† & & \\
\hline $0.5-1$ & 168 & 14085 & 11.9 & 85 & 10218 & 8.32 & $0.70(0.54 \text { to } 0.91)^{\star \star}$ & $0.46(0.33 \text { to } 0.62)^{\star \star \star}$ \\
\hline $1-2$ & 245 & 25831 & 9.48 & 154 & 18991 & 8.11 & 0.86 (0.70 to 1.05$)$ & $0.54(0.43 \text { to } 0.70)^{\star \star *}$ \\
\hline
\end{tabular}

${ }^{\star \star} \mathrm{P}<0.01,{ }^{* * *} \mathrm{P}<0.001$.

†Rate, incidence rate, per 1000 person-years; crude HR, relative HR.

$\ddagger$ Adjusting for age, gender, comorbidity of sleep disorder, diabetes, hypertension, hyperlipidaemia, mental disorders, alcohol-related illness, chronic kidney disease, gout, CAD and stroke, and ICS and OS medication.

CAD, coronary artery disease; ICS, inhaled corticosteroids; OS, oral steroids; PY, person-years.

(eg, IL-6 and C reactive protein levels) are tracked in many institutes during the course of ILD and pulmonary fibrosis to monitor drug use for immunodeficiency diseases. ${ }^{47} 48$ Cancer and ILD with respiratory failure are categorised as catastrophic diseases. ${ }^{49}$ These strict policies help explain the lack of biochemistry data in the NHIRD.

Table 6 Overall incidence of cancer (per 1000 person-years) and estimated HR in patients with interstitial lung disease and pulmonary fibrosis with statin compared with patients with interstitial lung disease and pulmonary fibrosis without statin by Cox proportional hazard model with time-dependent covariates in propensity score-matched sensitivity analysis

\begin{tabular}{|c|c|c|c|c|c|c|}
\hline \multirow[b]{3}{*}{ Site of cancer } & \multicolumn{4}{|l|}{ Statin } & \multirow[b]{3}{*}{ Crude HR (95\% Cl) } & \multirow[b]{3}{*}{ Adjusted HR $(95 \% \mathrm{Cl})$} \\
\hline & \multicolumn{2}{|c|}{ No $(n=10036)$} & \multicolumn{2}{|c|}{ Yes $(n=10036)$} & & \\
\hline & Case & Rate† & Case & Rate† & & \\
\hline Haematological malignancy & 68 & 1.44 & 39 & 0.74 & $0.53(0.36 \text { to } 0.79)^{\star \star}$ & $0.52(0.35 \text { to } 0.78)^{\star \star}$ \\
\hline Head and neck cancer & 109 & 2.30 & 60 & 1.13 & $0.52(0.38 \text { to } 0.71)^{\star \star \star}$ & $0.52(0.38 \text { to } 0.72)^{\star \star \star}$ \\
\hline Stomach & 62 & 1.31 & 64 & 1.21 & 0.96 (0.68 to 1.36$)$ & 0.98 (0.69 to 1.39$)$ \\
\hline Colon, rectum & 215 & 4.54 & 165 & 3.11 & $0.72(0.59 \text { to } 0.88)^{\star \star}$ & $0.73(0.59 \text { to } 0.89)^{\star \star}$ \\
\hline Liver & 245 & 5.17 & 88 & 1.66 & $0.33(0.26 \text { to } 0.42)^{\star \star \star}$ & $034(0.26 \text { to } 0.43)^{\star \star \star}$ \\
\hline Pancreas & 45 & 0.95 & 19 & 0.36 & $0.39(0.23 \text { to } 0.67)^{\star \star \star}$ & $0.39(0.23 \text { to } 0.67)^{\star \star \star}$ \\
\hline Lung & 174 & 3.67 & 160 & 3.02 & 0.86 (0.69 to 1.06$)$ & $0.88(0.71$ to 1.09$)$ \\
\hline Cervix & 36 & 1.41 & 11 & 0.38 & $0.28(0.14 \text { to } 0.55)^{\star \star \star *}$ & $0.27(0.14 \text { to } 0.54)^{\star \star \star}$ \\
\hline Endometrium & 30 & 1.17 & 22 & 0.75 & 0.67 (0.39 to 1.17 ) & 0.67 (0.38 to 1.16$)$ \\
\hline Ovary & 13 & 0.51 & 14 & 0.48 & 0.99 (0.47 to 2.11$)$ & 1.00 (0.47 to 2.13$)$ \\
\hline Prostate & 80 & 3.67 & 63 & 2.66 & 0.76 (0.54 to 1.05$)$ & 0.82 (0.59 to 1.15$)$ \\
\hline Bladder, kidney & 100 & 2.11 & 77 & 1.45 & $0.72(0.53 \text { to } 0.97)^{*}$ & $0.73(0.54 \text { to } 0.98)^{*}$ \\
\hline Brain & 8 & 0.17 & 9 & 0.17 & 1.05 (0.41 to 2.72$)$ & 1.02 (0.39 to 2.66$)$ \\
\hline Thyroid & 29 & 0.61 & 21 & 0.40 & 0.68 (0.39 to 1.18$)$ & 0.67 (0.38 to 1.17 ) \\
\hline Others & 80 & 1.69 & 54 & 1.02 & $0.63(0.45 \text { to } 0.89)^{\star \star}$ & $0.62(0.44 \text { to } 0.88)^{\star \star}$ \\
\hline
\end{tabular}

${ }^{*} \mathrm{P}<0.05,{ }^{* *} \mathrm{P}<0.01,{ }^{* * *} \mathrm{P}<0.001$

†Rate, incidence rate, per 1000 person-years; crude HR, relative HR.

$\ddagger$ Adjusting for age, gender, comorbidity of sleep disorder, diabetes, hypertension, hyperlipidaemia, mental disorders, alcohol-related illness, chronic kidney disease, gout, CAD and stroke, and ICS and OS medication.

CAD, coronary artery disease; ICS, inhaled corticosteroids; OS, oral steroids. 
The NHIRD also does not provide pathological and CT data. However, in Taiwan, ILD is generally diagnosed through CT and pathology tests. ${ }^{28}$ Another limitation of the present study is that we did not stratify the statins into lipophilic and hydrophilic statins for sensitivity analysis. A previous NHIRD study reported that lipophilic and hydrophilic statins can aid in the attenuation of risk of cancer. ${ }^{50}$ The comparison of a randomised control study, reverse causation, adjustments for causal intermediaries and depletion of susceptibles were the limitations of the aforementioned observational study. For example, statin use did not influence the risk of oesophageal, stomach, endometrial, ovarian, prostate, brain or thyroid cancer. One explanation is that observational studies that used the ICD-9-CM were unable to collect and adjust data relating to diet, exercise, socioeconomic status, smoking status, vitamin supplementation, and screening history for oesophageal, stomach, endometrial, ovarian, prostate, brain and thyroid cancer, all of which are potential confounders for the effect of statins on these cancers. Furthermore, the current cohort did not exhibit a particularly high incidence of lung cancer, which may be explained by the high proportion of patients with mildstage ILD. This is another limitation of the present study.

\section{CONCLUSION}

Statin use is associated with a lower risk of cancer incidence in those with ILD and pulmonary fibrosis.

\section{Author affiliations}

${ }^{1}$ Department of Family Medicine and Medical Research, Ditmanson Medical

Foundation Chia-Yi Christian Hospital, Chiayi, Taiwan

${ }^{2}$ China Medical University, Taichung, Taiwan

${ }^{3}$ School of Chinese Medicine, College of Chinese Medicine, China Medical University, Taichung, Taiwan

${ }^{4}$ Department of Chinese Medicine, China Medical University Hospital, Taichung, Taiwan

${ }^{5}$ Management Office for Health Data, China Medical University Hospital, Taichung, Taiwan

${ }^{6}$ College of Medicine, China Medical University, Taichung, Taiwan

${ }^{7}$ Graduate Institute of Biomedical Sciences, College of Medicine, China

MedicalUniversity, Taichung, Taiwan

${ }^{8}$ Department of Nuclear Medicine and PET Center, China Medical University Hospital, Taichung, Taiwan

${ }^{9}$ Department of Bioinformatics and Medical Engineering, Asia University, Taichung, Taiwan

${ }^{10}$ Center of Augmented Intelligence in Healthcare, China Medical University Hospital, Taichung, Taiwan

Contributors All authors have contributed significantly and are in agreement with the content of the manuscript. Conception and design: J-JY, C-HK. Administrative support: C-HK. Collection and assembly of data: J-JY, J-NL, C-LL, C-YH, C-HK. Data analysis and interpretation: J-JY, J-NL, C-LL, C-YH, C-HK. Manuscript writing: J-JY, J-NL, C-LL, C-YH, C-HK. Final approval of manuscript: J-JY, J-NL, C-LL, C-YH, C-HK.

Funding This study is supported in part by the Taiwan Ministry of Health and Welfare Clinical Trial Centre (MOHW110-TDU-B-212-124004), China Medical University Hospital (DMR-109-231, DMR-110-089), MOST Clinical Trial Consortium for Stroke (MOST 108-2321-B-039-003-) and Tseng Lien Lin Foundation, Taichung, Taiwan. No additional external funding was received for this study.

Disclaimer The funders had no role in the study design, data collection and analysis, decision to publish, or preparation of the manuscript.
Competing interests None declared.

Patient consent for publication Not required.

Ethics approval The NHIRD encrypts patient personal information to protect privacy and provides researchers with anonymous identification numbers associated with relevant claims information, including sex, date of birth, medical services received and prescriptions. Therefore, patient consent is not required to access the NHIRD. This study was approved to fulfil the condition for exemption by the Institutional Review Board (IRB) of China Medical University (CMUH104-REC2115-AR4). The IRB also specifically waived the consent requirement.

Provenance and peer review Not commissioned; externally peer reviewed.

Data availability statement Data may be obtained from a third party and are not publicly available. The dataset used in this study is held by the Taiwan Ministry of Health and Welfare (MOHW). The Ministry of Health and Welfare must approve our application to access this data. Any researcher interested in accessing this dataset can submit an application form to the Ministry of Health and Welfare requesting access. Please contact the staff of MOHW (Email: stcarolwu@mohw.gov.tw) for further assistance. Taiwan Ministry of Health and Welfare Address: No.488, Sec. 6 , Zhongxiao E. Rd., Nangang Dist., Taipei City 115, Taiwan (R.0.C.). Phone: +886-28590-6848. All relevant data are within the paper.

Supplemental material This content has been supplied by the author(s). It has not been vetted by BMJ Publishing Group Limited (BMJ) and may not have been peer-reviewed. Any opinions or recommendations discussed are solely those of the author(s) and are not endorsed by BMJ. BMJ disclaims all liability and responsibility arising from any reliance placed on the content. Where the content includes any translated material, BMJ does not warrant the accuracy and reliability of the translations (including but not limited to local regulations, clinical guidelines, terminology, drug names and drug dosages), and is not responsible for any error and/or omissions arising from translation and adaptation or otherwise.

Open access This is an open access article distributed in accordance with the Creative Commons Attribution Non Commercial (CC BY-NC 4.0) license, which permits others to distribute, remix, adapt, build upon this work non-commercially, and license their derivative works on different terms, provided the original work is properly cited, appropriate credit is given, any changes made indicated, and the use is non-commercial. See: http://creativecommons.org/licenses/by-nc/4.0/.

ORCID iDs

Jun-Jun Yeh http://orcid.org/0000-0002-4368-7880

Chia-Hung Kao http://orcid.org/0000-0002-6368-3676

\section{REFERENCES}

1 Tzouvelekis A, Karampitsakos T, Gomatou G, et al. Lung cancer in patients with idiopathic pulmonary fibrosis. A retrospective multicenter study in Greece. Pulm Pharmacol Ther 2020;60:101880.

2 Karampitsakos T, Tzilas V, Tringidou R, et al. Lung cancer in patients with idiopathic pulmonary fibrosis. Pulm Pharmacol Ther 2017;45:1-10.

3 Plummer M, de Martel C, Vignat J, et al. Global burden of cancers attributable to infections in 2012: a synthetic analysis. Lancet Glob Health 2016;4:e609-16.

4 Haas OA. Primary immunodeficiency and cancer predisposition revisited: embedding two closely related concepts into an integrative conceptual framework. Front Immunol 2018;9:3136.

5 Valencia JC, Egbukichi N, Erwin-Cohen RA. Autoimmunity and cancer, the paradox comorbidities challenging therapy in the context of preexisting autoimmunity. $J$ Interferon Cytokine Res 2019;39:72-84

6 Ansari MH, Ebrahimi M, Fattahi MR, et al. Viral metagenomic analysis of fecal samples reveals an enteric virome signature in irritable bowel syndrome. BMC Microbiol 2020;20:123.

7 Jurjus A, Eid A, Al Kattar S, et al. Inflammatory bowel disease, colorectal cancer and type 2 diabetes mellitus: the links. BBA Clin 2016;5:16-24.

8 Ojo AS, Balogun SA, Williams OT, et al. Pulmonary fibrosis in COVID-19 survivors: predictive factors and risk reduction strategies. Pulm Med 2020;2020:6175964.

9 Maringe C, Spicer J, Morris M, et al. The impact of the COVID-19 pandemic on cancer deaths due to delays in diagnosis in England, UK: a national, population-based, modelling study. Lancet Oncol 2020;21:1023-34.

10 Geisslinger F, Vollmar AM, Bartel K. Cancer Patients Have a Higher Risk Regarding COVID-19 - and Vice Versa? Pharmaceuticals 2020;13:143. 
11 Todd JL, Vinisko R, Liu Y, et al. Circulating matrix metalloproteinases and tissue metalloproteinase inhibitors in patients with idiopathic pulmonary fibrosis in the multicenter IPF-PRO registry cohort. BMC Pulm Med 2020;20:64

12 Samara K, Giannarakis I, Papanikoalou I. Overexpression of matrix metalloproteinase-7 (MMP-7) in bronchoalveolar lavage fluid (BALF) of IPF and lung cancer patients. Eur Resp J 2011;38:4761.

13 Raeeszadeh-Sarmazdeh M, Do LD, Hritz BG. Metalloproteinases and their inhibitors: potential for the development of new therapeutics. Cells 2020:9:1313.

14 Quintero-Fabián S, Arreola R, Becerril-Villanueva E, et al. Role of matrix metalloproteinases in angiogenesis and cancer. Front Oncol 2019;9:1370.

15 Wallace WAH, Fitch PM, Simpson AJ, et al. Inflammation-associated remodelling and fibrosis in the lung - a process and an end point. Int $J$ Exp Pathol 2007;88:103-10.

16 Raghu G, Nyberg F, Morgan G. The epidemiology of interstitial lung disease and its association with lung cancer. $\mathrm{Br} J$ Cancer 2004;91(Suppl 2):S3-10.

17 Beckwitt CH, Brufsky A, Oltvai ZN, et al. Statin drugs to reduce breast cancer recurrence and mortality. Breast Cancer Res 2018;20:144

$18 \mathrm{Xu} \mathrm{J}$, Fan J, Wu F, et al. The ACE2/Angiotensin-(1-7)/Mas Receptor Axis: Pleiotropic Roles in Cancer. Front Physiol 2017;8:276.

19 Zaleska M, Mozenska O, Bil J. Statins use and cancer: an update. Future Oncol 2018:14:1497-509.

20 Rasha F, Ramalingam L, Gollahon L, et al. Mechanisms linking the renin-angiotensin system, obesity, and breast cancer. Endocr Relat Cancer 2019;26:R653-72.

$21 \mathrm{Ham} \mathrm{I}-\mathrm{H}$, Oh HJ, Jin H, et al. Targeting interleukin-6 as a strategy to overcome stroma-induced resistance to chemotherapy in gastric cancer. Mol Cancer 2019;18:68.

22 Epstein Shochet G, Brook E, Eyal O, et al. Epidermal growth factor receptor paracrine upregulation in idiopathic pulmonary fibrosis fibroblasts is blocked by nintedanib. Am J Physiol Lung Cell Mol Physiol 2019;316:L1025-34.

23 Hondermarck H, Bartlett NW, Nurcombe V. The role of growth factor receptors in viral infections: an opportunity for drug repurposing against emerging viral diseases such as COVID-19? FASEB Bioadv 2020;2:296-303.

24 Nguyen P-A, Chang C-C, Galvin CJ, et al. Statins use and its impact in EGFR-TKIs resistance to prolong the survival of lung cancer patients: a cancer registry cohort study in Taiwan. Cancer Sci 2020;111:2965-73.

25 Fatehi Hassanabad A. Current perspectives on statins as potential anti-cancer therapeutics: clinical outcomes and underlying molecular mechanisms. Transl Lung Cancer Res 2019;8:692-9.

26 Fedson DS. Treating the host response to emerging virus diseases: lessons learned from sepsis, pneumonia, influenza and Ebola. Ann Trans/ Med 2016;4:421.

27 Bifulco M, Gazzerro P. Statins in coronavirus outbreak: it's time for experimental and clinical studies. Pharmacol Res 2020;156:104803.

28 Lai C-C, Wang C-Y, Lu H-M, et al. Idiopathic pulmonary fibrosis in Taiwan - a population-based study. Respir Med 2012;106:1566-74.

$29 \mathrm{Kim}$ J, Chun J, Lee C, et al. Increased risk of idiopathic pulmonary fibrosis in inflammatory bowel disease: a nationwide study. $J$ Gastroenterol Hepatol 2020;35:249-55.

30 Bailey JR, Bland PW, Tarlton JF, et al. IL-13 Promotes Collagen Accumulation in Crohn's Disease Fibrosis by Down-Regulation of Fibroblast MMP Synthesis: A Role for Innate Lymphoid Cells? PLoS One 2013;7:e52332.

31 Newnham A, Harris J, Evans HS, et al. The risk of cancer in HIVinfected people in Southeast England: a cohort study. Br J Cancer 2005;92:194-200.
32 Yeh J-J, Lin C-L, Kao C-H. Associations among chronic obstructive pulmonary disease with asthma, pneumonia, and corticosteroid use in the general population. PLoS One 2020;15:e0229484.

33 Catarata MJ, Ribeiro R, Oliveira MJ, et al. Renin-Angiotensin system in lung tumor and microenvironment interactions. Cancers 2020;12. doi:10.3390/cancers12061457. [Epub ahead of print: 0306 2020].

34 de Paula Gonzaga ALAC, Palmeira VA, Ribeiro TFS, et al. ACE2/ Angiotensin-(1-7)/Mas receptor axis in human cancer: Potential role for pediatric tumors. Curr Drug Targets 2020;21:892-901.

35 Ogawa H, Koyanagi-Aoi M, Otani K, et al. Interleukin-6 blockade attenuates lung cancer tissue construction integrated by cancer stem cells. Sci Rep 2017;7:12317

36 Faverio P, Bocchino M, Caminati A, et al. Nutrition in patients with idiopathic pulmonary fibrosis: critical issues analysis and future research directions. Nutrients 2020;12:1131.

37 Venkataraman T, Coleman CM, Frieman MB. Overactive epidermal growth factor receptor signaling leads to increased fibrosis after severe acute respiratory syndrome coronavirus infection. $J$ Virol 2017;91. doi:10.1128/JVI.00182-17. [Epub ahead of print: 1506 2017].

38 Akhtar S, Yousif MHM, Dhaunsi GS, et al. Angiotensin-(1-7) inhibits epidermal growth factor receptor transactivation via a Mas receptordependent pathway. Br J Pharmacol 2012;165:1390-400.

39 Erkan D, Willis R, Murthy VL, et al. A prospective open-label pilot study of fluvastatin on proinflammatory and prothrombotic biomarkers in antiphospholipid antibody positive patients. Ann Rheum Dis 2014;73:1176-80.

40 Nielsen SF, Nordestgaard BG, Bojesen SE. Statin use and reduced cancer-related mortality. N Engl J Med 2012;367:1792-802.

$41 \mathrm{Li}$ X, Sheng L, Liu L, et al. Statin and the risk of hepatocellular carcinoma in patients with hepatitis $B$ virus or hepatitis $C$ virus infection: a meta-analysis. BMC Gastroenterol 2020;20:98.

42 Melloni C, Kimmick GG, Oyekunle T. Abstract 15660: statin use is associated with increased overall survival in patients with colorectal cancer: findings from a cohort of 29,498 United States veterans. Circulation 2019;140(Suppl 1):A15660.

43 Mok EHK, Lee TKW. The pivotal role of the dysregulation of cholesterol homeostasis in cancer: implications for therapeutic targets. Cancers 2020;12:1410.

44 Liu J-C, Hao W-R, Hsu Y-P, et al. Statins dose-dependently exert a significant chemopreventive effect on colon cancer in patients with chronic obstructive pulmonary disease: a population-based cohort study. Oncotarget 2016;7:65270-83.

45 Liu S-F, Kuo H-C, Lin M-C, et al. Inhaled corticosteroids have a protective effect against lung cancer in female patients with chronic obstructive pulmonary disease: a nationwide population-based cohort study. Oncotarget 2017;8:29711-21.

46 Lin S-Y, Lin C-L, Lin C-C, et al. Association between angiotensinconverting enzyme inhibitors and lung cancer-a nationwide, population-based, propensity score-matched cohort study. Cancers 2020;12:747.

47 Wang C-H, Liu C-Y, Wan Y-L, et al. Persistence of lung inflammation and lung cytokines with high-resolution CT abnormalities during recovery from SARS. Respir Res 2005;6:42.

48 Shieh J-M, Tseng H-Y, Jung F, et al. Elevation of IL-6 and IL-33 levels in serum associated with lung fibrosis and skeletal muscle wasting in a bleomycin-induced lung injury mouse model. Mediators Inflamm 2019;2019:7947596

49 Lain W-L, Chang S-C, Chen W-C. Outcome and prognostic factors of interstitial lung disease patients with acute respiratory failure in the intensive care unit. Ther Adv Respir Dis 2020;14:1753466620926956.

50 Chen M-J, Tsan Y-T, Liou J-M, et al. Statins and the risk of pancreatic cancer in Type 2 diabetic patients--A population-based cohort study. Int J Cancer 2016;138:594-603. 